\title{
O LUGAR DA MULHER E DO NEGRO NO MERCADO DE TRABALHO NO PARÁ
}

Edna Castro* e Rosa Acevedo**

\section{Introdução}

O perfil do mercado de trabalho do Estado do Pará mostra alterações nas duas últimas décadas, decorrentes sobretudo da implantação de empreendimentos industriais de grande e médio porte, estimuladores de número expressivo de pequenas empresas prestadoras de serviços. Todavia a expansão decorrente desses novos investimentos e as flutuações do mercado, podem ser acompanhadas apenas através de dados estatísticos aproximativos. Para a Região Metropolitana de Belém (RMB), a qualidade das informações modificou-se positivamente com a realização da Pesquisa de Emprego \& Desemprego ${ }^{1}$. Os dados levantados estão organizados de forma agregada, inclusive totalizando informações de natureza diferente - grupos de cor - o que dificulta uma análise mais refinada desse material. Permitem, porém, identificar tendências e explorar algumas hipóteses que contribuiriam para esclarecer

\footnotetext{
* Dra. em Sociologia. Professora do Núcleo de Altos Estudos Amazônicos/Universidade Federal do Pará.

**Dra. em História. Professora do Núcleo de Altos Estudos Amazônicos/Universidade Federal do Pará.

1 Pesquisa de Emprego e Desemprego na Região Metropolitana de Belém. IDESP/SETEPS/SINE-PA, levantamento realizado de 1989 a 1995.
} 
mudanças ou permanências de alguns padrões de organização e de reestruturação do mercado de trabalho. As informações qualitatitivas e com corte por ramos - a exemplo de setores industriais como alimentação, construção civil e serviços - ajudariam a ampliar o conhecimento sobre a estrutura e a dinâmica do setor analisado e do mercado.

Neste artigo procuramos abordar, com base em fontes sobre emprego, censos demográficos e observações de campo em pesquisas anteriores sobre o perfil do emprego por setores de atividade e mais amplamente, sobre o mundo do trabalho nas empresas estudadas, dois ângulos do perfil ocupacional do Estado do Pará e da Região Metropolitana de Belém - o gênero e a raça ${ }^{2}$. Sob essa perspectiva buscamos compreender os mecanismos de dominação e as hierarquias presentes na sociedade e que são reproduzidas no mercado de trabalho.

A Pesquisa sobre Emprego \& Desemprego na RMB estabelece relações sobre a participação de grupos de gênero e raça na estrutura ocupacional. São as estatísticas mais desagregadas que obtivemos sobre o perfil do emprego. Entretanto, no referente à inserção de grupos de cor no mercado de trabalho é necessário destacar que essas diferenças, assinaladas de forma confusa, entre brancos e não brancos, acaba levando a uma polarização que impede de se captar os lugares ocupados por grupos raciais na estrutura ocupacional. Os não brancos, correspondem a $66 \%$ da população empregada, nos dados para a Região Metropolitana de Belém (Tabela 2). Os brancos, embora minoria, determinam a denominação dos segmentos que aí não se incluem. Exatamente porque não são brancos, são classificados nas estatisticas, pelo lugar em que se encontram nas representações estigmatizadas, sob o olhar de uma sociedade hierarquizada, cujos lugares sociais são definidos também pelo racismo. Silenciando a negritude ou outras condições raciais, são reconhecidos somente pela oposição ao branco.

\footnotetext{
2 Seguimos as observações analíticas de Verena Stock sobre a correnpondência entre a mudança de terminologia para designar as diferenças de cor e sexo, e o avanço teórico e político na explicitação desssas diferenças. Diz Stock que o "uso do termo "etnicidade" e da expressão "grupo étnico" para designar uma categoria de pessoas ligadas por traços comuns é recente, ao contrário do uso dos termos "raça" de origem muito mais antiga ... e "racismo", que se diz ter se tornado popular apenas no período entre as duas guerras mudiais". A categoria gênero começou a ser trabalhada como categoria de análise na década de 80. Diz a autora que nos anos 70, "a pesquisa feminista havia demonstrado que aquilo que então se chamava papéis sexuais variava amplamente em termos transculturais (Moore, 1988). Considera então que "o conceito analítico de "gênero" se destina a desafiar a máxima existencialista e universalista de que "a biologia é o destino. Ele transcende o reducionismo biológico, interpretando as relações entre homens e mulheres como formulações culturais resultantes da imposição de significados sociais, culturais e psicológicos sobre identidades sexuais" ( op cit).
} 
Quanto à categoria gênero, ela é concebida, também nas estatísticas, de forma naturalizada, como atributo biológico, ou seja, enfatizando a divisão por sexo, sem qualificar as diferenças nas ocupações, nos empregos e na posição de cada grupo na hierarquia social. Mulher tem sido uma atribuição desconectada da relação de poder existente na organização do trabalho. Inúmeros estudos, na área da sociologia do trabalho, no Brasil, tem revelado como se reproduzem as relações de dominação ao interior do mercado de trabalho ${ }^{3}$.

\section{Gênero, raça e classe: diferenças e desigualdades}

$\mathrm{Na}$ literatura das ciências sociais as questões de raça, gênero e classe foram em grande parte tratadas separadamente nas análises dos processos de desigualdade, marginalização, dominação e opressão. Os estudos sobre classes sociais trouxeram reflexões interessantes porém marcadas por um caráter generalista, abordando as contradições principais na sociedade capitalista ou privilegiaram enfoques sobre a dinâmica de uma determinada classe social. Neste caso, são exemplos os inúmeros trabalhos publicados sobre a classe operária, onde o olhar sobre as diferenças não ultrapassava o campo relativo a sua inserçao no processo de trabalho e no movimento sindical. As diferenças de gênero e raça e como estas interferem nas oportunidades de acesso no mercado de trabalho não constituiram tema de estudo a não ser a partir dos anos 80. Dai porque a compreensão sobre os processos de desigualdade de raça e de gênero exige uma abordagem que se afaste de qualquer forma de reducionismo, enfrentando uma perspectiva relacional.

O exame das questões de gênero isoladas das de raça e classe, deu uma impresssão de que as mulheres, enquanto mulheres, constituem, de certa forma, uma categoria social homogênea com interesses materiais divididos entre si, que podem fornecer uma base efetiva para a solidariedade e a luta. $\mathrm{O}$ exemplo clássico de tal abordagem é o trabalho de Caroline Moser no qual demonstrou como, durante certo tempo, a administração do desenvolvimento dos territórios de ultramar do govêrno britânico, utilizou essa abordagem como paradigma, para justificar o financiamento de projetos de ajuda. Moser desenvolve a problemática nos seguintes termos:

"A meta do planejamento voltado a questão de gênero é a emancipação das mulheres da sua subordinação e a consecção da igualdade, da equidade objetivando ampliar seu espaço de poder. Isso varia bastante em diferentes contextos dependendo do grau de subordinação

3 Ver entre outros: Elizabeth Souza Lobo: A Classe Operária Tem Dois Sexos. Ed. São Paulo (Brasiliense.1992. Cristina Bruschini - Mulher e Trabalho: Uma Avaliação da Década da Mulher. São Paulo. Nobel. 1985. Alice de Paiva Abreu - O Avesso da Moda - Trabalho à Domicício na Indústria de Confecções. SP. Hucitec. 1986. Helena Hirata: Le "modèle" japonais. Paris. Harmmatan. 1992. 
das mulheres enquanto categoria em relação ao status dos homens e também enquanto categoria. Homens e mulheres desempenham papéis diferentes na sociedade, sendo que as diferenças de gênero sao marcadas por determinações ideológicas, históricas, religiosas, étnicas, econômicas e culturais. Esses papéis mostram semelhanças e diferenças entre certas categorias sociais tais como a classe, a 'raça', a etnicidade e outras. As categorias sociais, portanto, diferenciam a experiência da desigualdade e da subordinação no âmbito da sociedade" (1993, 1-3).

É interessante observar que dentre as três categorias sociais, a autora menciona, en passant, a categoria de raça e a coloca entre aspas.

A validade conceitual e a relevância social de tal abordagem, há de ser questionada particularmente em sociedades multiraciais, como a Inglaterra, os Estados Unidos e o Brasil. Para evitar todo ou qualquer equívoco, a questão que deve ser enfrentada nessas sociedades é a seguinte: para as mulheres negras, são as mulheres brancas suas aliadas naturais, na construção da solidariedade através de uma luta contra todos os homens ou, então, são os homens negros seus aliados naturais na construção de uma solidariedade, numa luta contra a opressão racista em que as mulheres brancas são tão opressoras quanto os homens brancos? As abordagens feministas, nos anos 70, viam a mulher como categoria social indiferenciada do ponto de vista da raça. Algumas correntes do movimento feminista, não consideraram relevantes nem mesmo as diferenças de classe. As reações de grupos de mulheres negras que não se viam incluidas nas formulações das feministas brancas, respondem positivamente pela incorporação da opressão de raça como questão "qualificada" no debate sobre a desigualdade. Responderíamos que essa problemática so pode ser resolvida através do reconhecimento de identidades sociais múltiplas que são impostas a todos nós pela ontologia de nossa existência.

Construir uma teoria da diferença implica, como primeiro exercício, procurar dar conta da complexidade das relações decorrentes da interação entre gênero, raça e classe, através da qual se pode inferir que tanto a raça, quanto o gênero, somente podem ser referidas na sua relação com a classe. Verena STOLCKE, comenta que a

"desigualdade de gênero na sociedade de classes resulta de uma tendência bistoricamente especifica a "naturalizar" ideologicamente desigualdades sócio-econômicas prevalecentes". E acrescenta ainda: "tal como vejo, essa "naturalizacãa" é um subterfúgio ideológico destinado a conciliar o irreconciliável, on seja, o difundido "ethos" (ilusão) de igualdade de oportunidades para todos os sêres humanos, nascidos livres e iguais, com a existência real de desigualdades sócio-econômicas no interesse dos beneficiários destas" (1990).

Não é possível para um indivíduo decidir, de forma alguma, qual das diversas identidades determina a configuração do terreno social no qual sua vida se encaixa na identidade primária, através de um exercício de escolha pes- 
soal. A determinação da prioridade aqui não é somente relativa, mas também contextual. Para o mesmo indivíduo, a especificidade da identidade primária muda segundo o contexto. Tentaremos explicar essa idéia de forma mais concreta. No Brasil, algumas pessoas procuram revestir o racismo com roupagem aceitável, justificando-o de "cordial". Porém, as observações nos mostram que ele não é nem cordial e nem isento de violência.

Essa discussão nos conduz a concluir que nem a raça e nem o gênero são suficientes para definir a situação de classe de um indivíduo, mas apontam de forma expressiva para redefinir a compreensão sobre a diferença. Gênero e raça se articulam, na hierarquia social, através de fortes referências culturais, para formar e reproduzir a sociedade de classe e revelar as desigualdades de acesso ao poder, ao trabalho e à propriedade. Esse conjunto - classe, gênero e raça - determina a forma de ingresso e as habilidades que são movimentadas no mercado de trabalho (Humphrey:1987; Lovell, 1994)

No Brasil, em razão da grande miscigenação, as fronteiras entre as identidades raciais não são tão claramente definidas, como por exemplo nos EUA. A grande maioria de sua população, no sentido real, não é nem branca, nem negra. Mas ocupa um espectro amplo entre os dois polos. O polo branco certamente comparece com pouco mais de $30 \%$ da população total, se considerarmos as fontes estatísticas, embora se saiba que elas concorrem a uma sobrecontagem. No entanto esse polo detém o monopólio quase exclusivo do poder econômico e se reflete ocupando os lugares de maior prestígio no mercado de trabalho.

Para as mulheres desse segmento da população privilegiada, no âmbito dessa sociedade específica, a consciência da identidade primária devia ser a de gênero porque somente esta definiria suas desvantagens relativas, no segmento privilegiado do mercado de trabalho em relação aos homens da mesma classe e raça. No entanto, é bastante improvável que essas mulheres percebam sua identidade de interesses fundados no gênero como uma base concreta de consolidação da solidariedade com as mulheres no polo oposto, negro. A fonte primária de desvantagens que este último enfrenta, não brota de seu gênero e sim de sua condição de raça. Reforçado, em seguida, pela sua condição de classe. Esta condição de classe, ou seja, o fato de não conseguir alcançar os graus mais elevados da hierarquia de classe é naturalmente um produto de discriminação racial. Opera-se uma exclusão seletiva determinada pela raça, para os degraus mais elevados do mercado de trabalho, ao longo das gerações.

Estas mulheres teriam pouco a ganhar no reconhecimento da prioridade de uma identidade repousando sobre o gênero. Seu gênero poderá ter alguma relevância no que tange algumas desvantagens dentro da família e até 
na comunidade local. Mas sua raça lhe corta os acessos e as oportunidades de mobilidade ascendente no mercado de trabalho. Certamente que elementos anteriores e ligados a sua condição de classe colaboram para reduzir suas chances de ascensão social ao impor obstáculos desde a escola, onde uma crivagem é reiterada ao longo dos anos. Se trata de uma exclusão compartilhada por mulheres e homens negros. Mas, a principal identidade e, portanto, o ponto de referência para a mobilização política aqui é a raça e não o gênero.

A grande maioria da população brasileira é parda. Mas 'pardo' não é uma raça. O censo brasileiro não relata a situação correta pela inclusão de um grande número de indivíduos pardos na categoria brancos. Para as mulheres pardas com renda mais elevada a cor não é uma categoria excludente. $\mathrm{O}$ branqueamento ideológico poderá ser um meio para conquistar melhor colocação na hierarquia de poder e de status. Para essas mulheres, e em grau menor, para um pequeno número de mulheres negras com renda mais alta e para as mulheres brancas porém pobres, aparece aí uma fluidez maior na determinação da prioridade de identidade entre gênero e raça.

No Brasil, o ressurgimento da democracia eleitoral, em 1984, e a remoção das exigências para o direito de voto para os analfabetos, contribuiram para essa fluidez na medida em que contemplou segmentos até então excluidos, com a possibilidade de influenciar no jogo político. A construção de estruturas efetivas de mobilização política para assegurar os direitos das mulheres brasileiras necessitaria de uma compreensão mais clara da natureza dessa fluidez. Isto, por sua vez, requereria várias pesquisas empíricas. Pensando em articular variáveis que explicitem melhor tal problemática, propomos um modelo esquemático no qual encontram-se dois eixos. No horizontal, a variável renda, e no vertical, a variável cor.

Trata-se evidentemente de um modelo teórico, portanto geral, que não leva em conta fatores tais como o engajamento ideológico, que pode cruzar as linhas da raça. Contudo, o modelo mostra que uma mobilização política efetiva para o avanço das mulheres na sociedade brasileira, necessitaria de uma compreensão das diferentes sobre as formas como o gênero, a raça e a classe influenciam atitudes sociais da população.

A trajetória do movimento feminista no Brasil, mostrou o peso, na sua agenda, das questões referentes à discriminação racial. Ele conseguiu combinar reinvindações sobre as diferenças de gênero e raça, ainda que tardiamente e sobre uma perspectiva mais intelectual de classe média. Para o movimento negro, também no Brasil, a afirmação das desigualdades e das diferenças de raça e de classe, foram associadas às questões de gênero, porém com menos peso. O lugar do negro e da mulher negra no mercado de trabalho é um dos 
alvos priorizados no debate que relaciona, ao interior desse movimento, raça, gênero e classe.

A identidade se forma, para a mulher negra, seja na luta pela não discriminação da cor - portanto contra o racismo e a sociedade branca - ou na luta contra a dominação masculina. A particularidade do racismo no Brasil aparece justamente pela sua negação e obscurecimento dos confrontos com grupos diferenciados e produtos da missigenação. Apesar da maior parte da população não ser branca, se ganhou espaços nessa última década a visibilidade sobre a diferença de cor, deve-se à força do movimento negro e da luta de diversos segmentos discriminados na sociedade brasileira.

\section{Mudanças na estrutura produtiva, emprego mercado de trabalho no Pará}

As mudanças nas estruturas produtivas constituem tema pouco abordado nos estudos econômicos sobre o Pará. A análise dos impactos sobre o trabalho assalariado tem sido igualmente tratado de forma periférica, inclusive não associando mudanças as estruturas produtivas, formas de trabalho e modos de vida, com a condição de gênero e de raça. E muito menos com categorias ocupacionais presentes em processos de trabalho artesanal, reconhecidos por apresentar menor demarcação das diferenças de gênero e de raça.

A indústria regional opera sobre duas forças, uma de desestruturação dos setores ditos tradicionais, e outra, de redimencionamento da estrutura produtiva com a emergência ou implantação de novos setores, a exemplo do mínero-metalúrgico. Emergiram nas duas últimas décadas, um número expressivo de novos setores econômicos, ramos empresariais e ocupações profissionais. Mas observa-se também, forte tensão entre as antigas estruturas produtivas, sobretudo consolidadas nas formas artesanais de trabalho e as novas, que introduziram inovações tecnológicas e de gestão do trabalho.

Nesse período, os setores que mais interferiram na geração do emprego industrial no Pará foram: madeira, construção civil, mineração, síderometalúrgico e alimentar. Tal dinamização empresarial foi produto de planos governamentais e incentivos fiscais de natureza diversa. Em todos esses setores, com exceção do indústria alimentar, predominou largamente uma relação emprego/sexo masculino positiva, pois a oferta de emprego se direcionou largamente à mão de obra masculina. A exemplo, os grandes projetos de mineração e hidrelétricos instalados no Pará absorveram na fase de instalação, cerca de 70.000 empregados, basicamente engajados para trabalhar nos canteiros de obras em diferentes ocupações. Os empreendimentos a que nos referimos são: Hidrelétrica de Tucuruí, Projeto Ferro Carajás, Ferrovia Carajás, Albras- 
Alunorte e Mineração Rio do Norte. Foram contratados por dezenas de firmas prestadoras de serviços às grandes empreiteiras como a Camargo Corrêa e a Andrade Gutierrez. O deslocamento desses trabalhadores em direção aos grandes canteiros de obras. Corresponde a um tipo de mobilidade do trabalho que se diferencia por se tratar de áreas de ocupação industrial novas. Esse processo de mobilidade do trabalho teve expressão sobretudo no final da década de 70 e ao longo dos anos 80.

Os Planos de Desenvolvimento - Nacionais e Regionais - incluiram como meta a criação de empregos, sem explicitar sua natureza e as distinções do perfil de trabalhadores requeridos por sexo, cor, qualificação, estado civil ou naturalidade. O planejamento regional e as políticas empresariais operam aparentemente, e so aparentemente, com indistinções no recrutamento de trabalhadores. O emprego foi adotado como legitimador da positividade do empreendimento, do ponto de vista do planejamento. Em quaisquer circunstâncias, emprego e renda são partes integrantes da ideologia do desenvolvimento.

A série de planos de desenvolvimento da Amazônia carece de uma rigorosa análise sobre o emprego gerado e seus impactos sobre o mercado de trabalho, particularmente nos municípios onde se instalaram os principais empreendimentos. Mas essa ótica terá de incorpora, de um lado, o emprego e os atributos requeridos ao trabalhador; de outro lado, destacaria as diferentes políticas empresariais. Através disso é possível entender as práticas de recrutamento por gênero e raça e suas interferências na segmentação do mercado de trabalho.

O Estado do Pará constittui uma região de expansão do regime assalariado, enquanto fronteira de recursos. A geração do emprego foi direcionada, na década de 70 , pelos setores industrial e de serviços absorvendo número expressivo de mulheres. Nas décadas posteriores, os empreendimentos mais expressivos na geração de emprego, absorveram maciçamente mão de obra masculina.

As observações nos permitem afirmar que as atividades desenvolvidos na fase de implantação dos empreendimentos citados, absorveram nos canteiros de obras uma força de trabalho sobretudo masculina, mas indistinta do ponto de vista da cor. Porém nos limites do trabalho temporário, incorporando grande contingente de trabalhadores migrantes. Nessa etapa não era procedimento da empresa ou das suas sub-contratadas, realizar processos classificatórios da mão de obra, com exceção de qualidades físicas e distribuição em faixas etária - entre 20 a 40 anos, prioritariamente. São qualidades diferentes daquelas que seriam exigidas no processo de organização produtivo poste- 
rior, quando o empreendimento recrutaria seu quadro permanente. Neste caso, obedece a critérios de capacidade profissional, experiência e qualificação, mas também incorpora outros atributos tais como cor, sexo e classe. A empresa se apóia em valores que estruturam as hierarquias conforme os sistemas de representação existentes na sociedade. A oferta de emprego por parte da empresa obedecerá a uma política de seleção, recrutamento e formação para seus quadros de operadores, técnicos, chefias e gerências. Essa política altera-se nas diferentes fases de funcionamento do empreendimento, quando se processam distinções. A combinação - distinção e atributos - permite aumentos de produtividade, desenvolve a competitividade e aprimora a adaptabilidade aos processos de trabalho. O emergente perfil ocupacional não foi indiferente ao sexo e à raça. As formas de segregação e exclusão tenderam a reproduzir processos tradicionais de segregação.

As intervenções empresariais e governamentais reforçaram modelos de segregação de grupos de cor. As afirmações quanto à discriminação e exclusão do negro de empregos melhor remunerados e mais qualificados, constitui questão delicada, pois os dados disponíveis não estão direcionados à explicitação da questão racial, muito ao contrário. Mas se os dados obscurecem a cor em categorias confusas - pardos, não brancos, por exemplo - eles também revelam sobre a disciminação dos atributos de cor. Nossas observações ao longo de pesquisas anteriores, tem mostrado sobretudo os lugares onde homens e mulheres negras não estão: nas ocupações melhor remuneradas e nos status mais prestigiados do mercado de trabalho.

$\mathrm{Na}$ medida que os grandes empreendimentos entram em fase de funcionamento, o perfil do recrutamento de homens e mulheres não se altera de forma significativa pois as ocupações dos setores mineral e sídero-metalúrgico orientam-se à demanda de trabalhadores do sexo masculino. Os 4 maiores empreendimentos àcima citado e cunhados como "grandes projetos"-, empregavam até inicio dos anos 90, cerca de 18.000 pessoas no Pará. Após uma fase de reestruturação do modelo de gestão e adoção de uma racionalidade que se adequa às técnicas de qualidade total e juste à temps, são absorvidos apenas cerca de 12.000 empregados, tendo havido uma redução em torno de $1 / 3$ do total dos trabalhadoresa. Desse total, tanto no início do empreendimento quanto na atualidade, apenas um percentual em torno de $10 \%$ corresponde a empregos femininos. Entre as empresas subcontratadas, onde o emprego é mais precário, há maior absorção de mulheres em setores administrativos e de serviços.

As exceções da geração do emprego em empreendimentos industriais que absorvem a mão de obra feminina, na Amazônia em geral e não somente no Pará, ficam restritas ao setor eletro-eletrônica, em Manaus, e a empreendi- 
mentos de menor porte, sobretudo no setor alimentar, como as indústrias de beneficiamento de pescado, de palmito e de bebida, setores nos quais já era tradição a absorção significativa do trabalho feminino ${ }^{4}$. O setor eletroeletrônico absorveu na fase áurea da Zona Franca de Manaus um número expressivo de mulheres, levando inclusive a definir um comportamento bem particular no mercado de trabalho e no perfil das lutas sindicais encaminhadas pelo operariado. No momento, esse contingente está bastante reduzido seja pela redefinição do papel dessas indústrias na economia nacional, seja como resultado da implantação de novo modelo de gestão. Um dos resultados mais importantes do referido modelo é a redução da mão de obra e, consequentemente, dos custos de operacão. Por outro lado, os empreendimentos industriais tradicionais que empregam importante contingente de mão de obra feminina, no Pará, vêm atravessando dificuldades. Alguns deles entraram em falência nos últimos 5 anos ou estão funcionando com média capacidade, precarizando ainda mais o mercado de trabalho absorvedor de mulheres.

Na década de 80 os dados do Censo Demográficos mostram evidências importantes acerca do desigual acesso de mulheres no mercado de trabalho. As tabelas 1 e 2 mostram que somente $42 \%$ das mulheres tinham emprego regular para 63\% de homens. Quanto à posição de homens e mulheres na ocupação os dados revelam o seguinte: 1) Apenas $0,6 \%$ das mulheres estavam na condição de empregadoras para $1,5 \%$ dos homens. O status de empregador também é um status de poder; 2) Entre os trabalhadores por conta própria $46 \%$ eram homens para somente $20 \%$ das mulheres. Isso significa que um número importante delas está excluido dos setores autônomos por conta própria; 3) Apenas 12\% das mulheres exerciam emprego não remunerado para $6 \%$ dos homens; 4) Metade das mulheres economicamente ativas estavam concentradas no setor de prestação de serviços e nas atividades sociais as quais em geral tem menor remuneração e são as mais exploradas no mercado de trabalho; 5) A presença de mulheres nos setores relativamente modernos e melhor pagos, a exemplo de setores da indústria de transformação e outras atividades industriais, aparece extremamente limitada.

4 Entre outros ver os trabalhos de Nelson do Vale Silva " Cor e processo de realização sócioeconômica. In: Silva, L.A.M.et al. Movimentos Sociais Urbanos, minorias étnicas e outros estudos. Brasília. ANPOCS - Revista de Ciências Sociais, 1983; e Lúcia Oliveira, Rosa Porcaro e Tereza Araújo - O lugar do negro na força de trabalho. Rio de Janeiro. FIBGE, 1981. Rosa Acevedo e Edna CastroNegros do Trombetas. Belem, UFPA, 1993. Carlos A. Hasenbalg - Discursos sobre a raça: pequena crônica de 1988. Rio de Janeiro, Estudos Afro-Asiáticos, n 20, jun/1991; e O negro na Indústria: proletarização tardia e desigua. Aguas de São Pedro, ANPOCS (GT Processo de Trabalho e Reinvindicações Sociais). 1991; L. Sansone - Cor e Trabalho Entre os Negros Mestiços de Classe Baixa em Diferentes Gerações. Salvador, Revista Análise \& dados. O Negro, vol.3, n 4, 1994. 
Tabela 1 - Pessoas Economicamente Ativas, segundo Sexo,setor de atividade e posição na ocupação principal - 1980

\begin{tabular}{l|r|r|r|r|r|r}
\hline \multirow{2}{*}{$\begin{array}{c}\text { Setor de atividade } \\
\text { e posição na } \\
\text { ocupação principal }\end{array}$} & \multicolumn{1}{|c|}{ Homens } & \multicolumn{1}{c}{ Mulheres } & \multicolumn{2}{c}{ Total } \\
\cline { 2 - 7 } & \multicolumn{1}{|c|}{ Abs. } & \multicolumn{1}{c}{$\%$} & \multicolumn{1}{c}{ Abs. } & \multicolumn{1}{c}{$\%$} & \multicolumn{1}{c}{ Abs. } & \multicolumn{1}{c}{$\%$} \\
\hline $\begin{array}{l}\text { Trabalhador } \\
\text { Agrícola Volante }\end{array}$ & 21.909 & 2.7 & 3.032 & 1.5 & 24.941 & 2.5 \\
\hline Parceiro ou Meeiro & 9.703 & 1.2 & 210 & 0.1 & 9.913 & 0.9 \\
\hline Empregado & 333.253 & 41.8 & 130.750 & 63.2 & 464.003 & 46.2 \\
\hline Empregador & 12.190 & 1.5 & 1.279 & 0.6 & 13.469 & 1.3 \\
\hline Conta Própria & 363.686 & 45.6 & 41.247 & 19.9 & 404.933 & 40.3 \\
\hline Não Remunerado & 47.911 & 6.0 & 25.254 & 12.2 & 73.165 & 7.3 \\
\hline Sem Declaração & 8.584 & 1.1 & 5.121 & 2.5 & 13.705 & 1.4 \\
\hline \hline Total & 797.236 & 100.0 & 206.893 & 100.0 & 1.004 .129 & 100.0 \\
\hline \hline
\end{tabular}

Fonte: IX Recenseamento Geral - 1980 / IBGE 
Tabela 2 - Pessoas Economicamente Ativas, segundo sexo, setor de atividade e ocupação principal

\begin{tabular}{|c|c|c|c|c|c|c|}
\hline \multirow{3}{*}{$\begin{array}{l}\text { Setor de Atividade e } \\
\text { ocupação principal }\end{array}$} & \multicolumn{6}{|c|}{ Sexo } \\
\hline & \multicolumn{2}{|c|}{ Homens } & \multicolumn{2}{|c|}{ Mulheres } & \multicolumn{2}{|c|}{ Total } \\
\hline & Abs. & $\%$ & Abs. & $\%$ & Abs. & $\%$ \\
\hline $\begin{array}{lll}\text { Atividades Agrop., } & \text { de } \\
\text { Extração Vegetal e Pesca } & \end{array}$ & 395.485 & 48.7 & 45.183 & 21.1 & 440.668 & 43.0 \\
\hline Indústria de Transformação & 80.341 & 9.9 & 14.614 & 6.8 & 94.955 & 9.2 \\
\hline Indústria da Construção & 64.611 & 7.9 & 1.474 & 0.7 & 66.085 & 6.4 \\
\hline Outras atividades industriais & 20.399 & 2.5 & 1.016 & 0.5 & 21.415 & 2.1 \\
\hline Comércio de Mercadorias & 77.749 & 9.5 & 22.438 & 10.5 & 100.187 & 9.7 \\
\hline Transportes e Comunicação & 38.130 & 4.7 & 2.176 & 1.0 & 40.306 & 3.9 \\
\hline Prestação de Serviços & 55.939 & 6.9 & 64.307 & 30.0 & 120.246 & 11.7 \\
\hline Atividades Sociais & 17.149 & 2.2 & 42.793 & 20.0 & 59.942 & 5.8 \\
\hline Administração Pública & 33.915 & 4.1 & 7.134 & 3.3 & 41.049 & 4.0 \\
\hline Outras Atividades & 13.518 & 1.7 & 5.758 & 2.7 & 19.276 & 1.9 \\
\hline Procurando Trabalho & 15.608 & 1.9 & 7.126 & 3.3 & 22.734 & 2.2 \\
\hline Total & 812.844 & 100.0 & 214.019 & 100.0 & 1.026 .863 & 100.0 \\
\hline
\end{tabular}

Fonte: IX Recenseamento Geral - 1980 / IBGE

Nessa perspectiva de análise somos levados a concluir pela não indiferenciação dos programas governamentais, e logo do planejamento enquanto técnica de intervenção em dada região, na constituição de novos lugares sociais, reafirmando as diferenças de raça e de gênero no mercado de trabalho.

\section{Mercado de Trabalho na Região Metropolitana de Belém}

A Região Metropolitana de Belém evidencia de diversas formas o processo de expansão e diversificação da estrutura industrial que se desenvolveu no Estado do Pará a partir dos anos 80. Primeiro, por ter recebido a implantação dos Distritos Industriais de Ananindeua e de Icoaraci. Segundo, essa instalação de indústrias reflete os impactos da política de incentivos fiscais. Terceiro, a Região Metropolitana de Belém torna-se o centro receptivo de mudanças conjunturais no mercado regional. A criação de empresas na nova estrutura produtiva - como a ALBRAS, do setor mínero-metalúrgico - tem efeitos diretos na composição do mercado de trabalho urbano e sobretudo, na forma de organização das categorias de trabalhadores.

Até 1987, a Região Metropolitana de Belém concentrava 64\% das empresas do setor gráfico, $35 \%$ do ramo de produtos alimentares e $32 \%$ das 
empresas imobiliárias, em relação às atividades industriais do Estado do Pará. Esses ramos que representam estruturas de produção artesanais na maior parte, são aqueles que absorvem um número mais expressivo de mulheres.

Mulheres e negros constituem parte importante do mercado de trabalho em diferentes ramos instalados na RMB. Nas conjunturas de aumento do desemprego (oculto e aberto) a incidência maior ocorre entre as mulheres nas faixas etárias de 10 a 17 anos e de 25 a 39 anos. Esta tendência observou-se no $1^{\circ}$ semestre de 1995.

Pesquisas anteriores revelaram ter havido discreto aumento da participação de mulheres na PEA, entretanto é marcante a ausência de detalhamento quanto à qualidade desses empregos. As estatísticas produzidas colocam inicialmente problemas para sua leitura referente à construção das categorias. Embora encontre-se a distribuição por sexo, falta estabelecer as crivagens por salário e estrutura ocupacional do emprego.

A Tabela 4 revela que de 1989 à 1995 houve um incremento do emprego de mulheres na Região Metropolitana de Belém, portanto apresentando uma tendência à alteração da presença de homens e mulheres no mercado de trabalho. O aumento da PEA feminina é de $42,8 \%$ para $44,0 \%$, embora tenha chegado em 1994, ao percentual de 46,9. Deve ser considerado, porém, que a população feminina da RMB é expressivamente maior em relação aos homens. As mulheres representam $1 / 3$ da PEA. Os dados censitários (1991) para a RMB revelam que para um total de 1.967 .880 habitantes, $52 \%$ eram mulheres, como pode ser observado na Tabela 3.

Tabela 3 - População da RMB segundo PE $A$ e a INEA

\begin{tabular}{l|c|c|c|c|c|c}
\hline & \multicolumn{2}{|c|}{ Masculino } & \multicolumn{2}{c|}{ Feminino } & \multicolumn{2}{c}{ Total } \\
\hline & Abs. & $\%$ & Abs. & $\%$ & Abs. & $\%$ \\
\hline PEA & 653.665 & 68.7 & 355.390 & 35.0 & 1.009 .055 & 51.3 \\
\hline INEA & 287.967 & 30.3 & 660.818 & 65.0 & 958.825 & 48.7 \\
\hline Total & 951.632 & 100.0 & 1.016 .208 & 100.0 & 1.967 .880 & 100.0 \\
\hline
\end{tabular}

Fonte: PNAD - 1990

A mesma tabela atribui um aumento da participação na PEA de não brancos, que passa de 65,4\% em 1989 para 73,1\%. Aqui se estabelece uma situação crítica de leitura dos dados, pois é conhecido a presença importante de descendentes de grupos indígenas na população do Pará e da RMB, embora seja também significativa a população negra. Da variação de cor - pardos, mulatos, negros, brancos - pouco podemos compreender com os dados da tabela citada, pois mesmo entre os brancos podem estar incluidos alguns " pardos" ou "mulatos" em condição social elevada. 
Os dados da Tabela 5 demonstram uma tendência à redução na idade de ingresso no mercado de trabalho, para homens e mulheres. Porém em 1994 e 1995 entram relativamente menos homens na menor faixa etária que mulheres.

Tabelas 4: Emprego na RMB por Sexo, Cor e Tempo de Residência

\begin{tabular}{|r|r|r|r|r|r|r|r}
\hline \multirow{2}{*}{ Anos } & \multicolumn{2}{|c|}{ Sexo } & \multicolumn{2}{c|}{ Cor } & \multicolumn{2}{c|}{$\begin{array}{c}\text { Tempo de } \\
\text { Residência }\end{array}$} & \multirow{2}{*}{ Total } \\
\hline & Masc. & Fem. & Branco & $\begin{array}{c}\text { Não } \\
\text { Branco }\end{array}$ & $\begin{array}{c}\text { Até 3 } \\
\text { anos }\end{array}$ & $\begin{array}{c}\text { + de 3 } \\
\text { anos }\end{array}$ & \\
\hline 1989 & 57.2 & 42.8 & 34.6 & 65.4 & 7.8 & 92.2 & 100.0 \\
\hline 1990 & 56.9 & 43.1 & 34.1 & 65.9 & 7.3 & 92.7 & 100.0 \\
\hline 1991 & 57.2 & 42.8 & 31.2 & 68.8 & 5.9 & 94.0 & 100.0 \\
\hline 1992 & 58.9 & 41.1 & 29.3 & 70.7 & 5.1 & 94.9 & 100.0 \\
\hline 1993 & 57.8 & 42.2 & 29.9 & 70.1 & 5.2 & 94.8 & 100.0 \\
\hline 1994 & 61.4 & 46.9 & 30.8 & 69.2 & 5.9 & 94.1 & 100.0 \\
\hline 1995 & 56.0 & 44.0 & 26.9 & 73.1 & 5.5 & 94.5 & 100.0 \\
\hline
\end{tabular}

Fonte: Pesquisa de Emprego e Desemprego na RMB - 1989/1995

Tabela 5: População Empregada na RMB por Sexo e Faixa Etária

\begin{tabular}{l|r|r|r|r|r|r|r|r|r}
\hline \multirow{2}{*}{ Anos } & \multicolumn{4}{|c|}{ Masculino } & \multicolumn{4}{|c|}{ Feminino } & \multirow{2}{*}{ Total } \\
\cline { 2 - 10 } & $10-17$ & $18-24$ & $25-39$ & +40 & $10-17$ & $18-24$ & $25-39$ & +40 & \\
\hline 1989 & 4.6 & 13.8 & 23.2 & 15.7 & 3.2 & 11.0 & 18.2 & 10.5 & 100.0 \\
\hline 1990 & 3.8 & 13.5 & 23.2 & 16.4 & 3.2 & 10.8 & 18.4 & 10.9 & 100.0 \\
\hline 1991 & 2.9 & 12.7 & 23.4 & 18.1 & 2.8 & 10.3 & 18.0 & 11.7 & 100.0 \\
\hline 1992 & 2.0 & 11.6 & 27.3 & 18.0 & 2.1 & 9.2 & 18.8 & 11.0 & 100.0 \\
\hline 1993 & 1.7 & 12.2 & 26.0 & 18.0 & 2.0 & 9.8 & 18.9 & 11.4 & 100.0 \\
\hline 1994 & 1.6 & 11.9 & 24.4 & 18.9 & 2.1 & 9.5 & 19.3 & 12.4 & 100.0 \\
\hline 1995 & 1.9 & 10.9 & 25.6 & 17.6 & 2.3 & 8.8 & 19.9 & 13.0 & 100.0 \\
\hline
\end{tabular}

Fonte: Pesquisa de Emprego e Desemprego na RMB - 1898/1995

É importante situar a seletividade sexual e a seletividade racial em relação a setores. Mulheres e negros ingressam em número relativamente menor em setores organizados sob forma capitalista (médias e grandes empresas), enquanto refugiam-se no setor artesanal e da pequena indústria. Neste nível opera o padrão de escolaridade de forma menos excludente. Enquanto nas indústrias mínero metalúrgicas as mulheres trabalhadoras são em número menor, em setores como têxtil e alimentação (castanha, palmito, pesca etc.) a participação feminina aumenta. O setor oleiro, no Pará, reservou um lugar de 
trabalho importante para mulheres e hoje ele tem menor expressão, sem vigor no conjunto da produção da indústria de construção civil, não tendo sido contemplada pela política de incentivos fiscais.

Contrariamente às políticas governamentais dos anos 60 e 70 para essa região, que dava prioridade à exploração de madeira e do gado, o Estado vai garantir nos anos 80 os interesses do setor industrial, particularmente os mineral e siderúrgico. A descoberta de riquezas minerais acelera as negociações e a aceitação dos primeiros projetos indutriais no setor de beneficiamento primário de minérios de ferro, maganês, bauxita, ouro e cobre, além da produção de alumínio, gusa e ligas. Dentre os grandes programas governamentais pensados para a Amazônia nessas últimas décadas, o Grande Carajás, extinto como o foi criado, por ato oficial do govêrno, se distingue dos demais pelo montante dos investimentos ali aplicados e o caráter de integração entre empreendimentos de natureza diversa: mineração, indústria, exploração vegetal, agro-pecuária e infra-estrutura portuária e de transporte. Também se distingue, por apresentar maior pretensão territorial e pelo poder direto ou simbólico exercido sobre essa extensa região pelo Companhia Vale do Rio Doce, somente justificável pelos interesses de diversificação setorial, fato confirmado ao longo desses anos.

O exame dos dados sobre o perfil de emprego dessas empresas bem como de suas sub-contratadas, revela que tem interferido com suas políticas, na recomposição das estruturas produtivas locais e no mercado de trabalho. Observa-se por exemplo, a diversificação de ramos de atividade, ocupações, qualificações, salários. Mas também novas formas de gestão, ocupando essas empresas um papel importante no processo de expansão do regime salarial, marcadamente em regiões de fronteira, pois ao se implantarem com relativa concentração geográfica, concentram-se também os impactos sobre o mobilização de mão-de-obra orientada para o mercado formal de trabalho.

\section{Conclusão}

A análise do mercado de trabalho no Estado do Pará e na RMB realizada através das categorias gênero e cor abre possibilidades de indicar a natureza das variações na estrutura do emprego. Esse caráter apenas indicativo está dado pela precariedade das estatísticas existentes. A série de restrições apontadas para o tratamento dessas variáveis nos registros censitários e nas pesquisas sugere a importância de modificações dos modelos de levantamentos e das variáveis adotadas. As categorias branco/não branco apresentam-se inapropriadas para captar as composições étnico-sociais da população e dos indicadores de emprego/desemprego. Ainda admitindo essa polarização como 
fonte para interpretar os fenômenos do mercado de trabalho, seria necessário acurar informações dentro do mesmo padrão no relativo às estimativas sobre ocupados, desempregados e inativos. Essa montagem pode ser de interesse para discutir situações, apenas supostas, de segregação racial, que operaria no ingresso no mercado de trabalho e em fases do denominado "encolhimento do mercado de trabalho".

A fase de expansão do emprego produz uma flexibilização favorável a mulheres e negros, entretanto, como vimos anteriormente, em fase de "encolhimento", os fatores que conduzem esses grupos para o desemprego e para inativida operam de forma seletiva. Ao nível das informações que permitam esclarecer esses movimentos parece imprescindível abordar o mercado de trabalho informal, buscando estabelecer as relações que se estabelecem entre esses segmentos seccionados do mercado.

A precariedade do emprego para mulheres e negros no Estado do Pará e na RMB corresponde a oferta restritiva de empregos nos novos

setores dominantes da economia. O ramo mínero-metalúrgico fomenta um número reduzido de empregos, reafirmando o seguinte: a) perfil de escolaridade. A ALBRAS começou a exigir o segundo grau completo para seu quadro de operários; b) faixas etárias mais baixas; c) empregados na grande maioria do sexo masculino. Uma outra empresa contratou 27 jovens mulheres para o setor de produção que ficaram reduzidas a cinco operárias na fase de enxugamento do quadro. A empresa Mineração Rio do Norte contratou cerca de 30 trabalhadores negros de um conjunto de 2.000 empregados, ainda que o empreendimento esteja incrustado no meio de comunidades negras, no Rio Trombetas.

O processo de terciarização reveste-se de extrema importância na análise da reestruturação produtiva e seus efeitos sobre mulheres e negros. A tendência é reproduzir os modelos da firma, entretanto o fato de oferecer, em média, salários menores e empregos instáveis pode ter um resultado a nivel de contratação de desempregados da grande empresa. Nesse sentido, a expansão de empresas médias e pequenas abre espaço para reabsorção dos grupos mais afetados por decisões dessas empresas. As dinâmicas da grande empresa e do processo de terciarização pode ter resultado complementar, absorvendo operários e operárias com experiência no ramo, muitas vezes com um nível de especialização dado pela empresa. $O$ fato dessas empresas operarem em atividades profissionais novas as torna exclusivas pois somente elas e as terciarizadas podem demandar essa formação, daí o poder de contratação e demissão. 
Os setores industriais e de serviço "tradicionais" mostram um comportamento relativamente estável no relativo à demanda de mão de obra e de preferência em relação aos ofertantes de emprego. Entretanto, este setor é frágil e vulnerável à crise ou alteração das condições para seu funcionamento (aumento das taxas bancarias, recorte do financiamento, diminuição das vendas). O setor da construção civil com suas formas de funcionamento características (capitalização, temporalidade, escolaridade, salários e recrutamento) é indicador relevante do emprego e desemprego. Tem sido o setor mais expressivo no acolhimento de grupos raciais colocados a margem da empresa moderna, na sua fase de instalação produtiva. A flexibilidade e versatilidade desse setor precisa ser estudado como leitura a contrapelo da rigidez das estruturas empresarias novas.

As reflexões sobre o lugar da mulher e do negro no mercado de trabalho tal como foi aqui conduzido sugere apenas um campo abrangente de pesquisa. O exercício conseguiu apontar dimensões menos frequentes na análise, embora extremamente importantes para fornecer evidências sobre a rigidez da estrutura do emprego que aciona mecanismos semelhantes da estrutura hierarquizada da sociedade brasileira. A quantidade e ainda a igualdade de oportunidades de emprego que sugerem os planos de desenvolvimento constituem uma ficção, e as empresas agem sobre o mercado de trabalho verticalizando formas de seleção discriminatória da força de trabalho. Mulheres ocupam lugares à margem da dinâmica do emprego, como foi visto nas estatísticas

Os Sindicatos de Trabalhadores - da Construção Civil, da Madeira, da Alimentação e o Metal Base - os mais importantes representando a indústria no Pará, se tem na sua agenda de luta a questão de gênero, tem estado menos alerta para responder as de raça. $\mathrm{Na}$ Albras, a acorrência de casos de leococemia, mostra curiosamente como podem filtrar-se as diferenças de cor. Ante o aumento do número de afetados pos essa doença do trabalho, a gerência da fábrica atribuiu a fatores genéticos da população negra. As qustões de raça, nessa oportunidade, alertaram para dados não frequentemente revelados no interior das firmas. O "racismo cordial" tem barreiras para implantar-se no mercado de trabalho e as práticas mostram intolerância e segregação, o que, em todo caso, está oculto no sistema de estatísticas que poderiam ajudar ao discernimento desses problemas sociais. Fica claro que na sociedade de classes, certas desigualdades socialmente relevantes - como raça e gênero - são marcadas e legitimadas por uma explicação que as representa como tendo raízes nas diferenças naturais, diferenças somente visibilizadas por fortes processos políticos, a exemplo do que se tem observado nessas tres últimas décadas, nas propostas das diferentes correntes integrantes dos movimentos feminista e negro. Porém os fatos nos mostraram que não foram suficientes 
para modificar as estruturas de reprodução do racismo e do machismo no mercado de trabalho.

\section{Notas}

5 - Ver: Edila Moura, Edna Castro e Maria Lúcia Maia - Utilização do Trabalho Feminino nas Indústrias de Belém e Manaus. Belém, Cadernos do SEPEQ/NAEA/UFPA, $\mathrm{n}^{\circ} 13,1995$. Trata-se de um estudo sobre as industrias de castanha, fumo, madeira, palmito, pescado e eletroeletrônica, atividades que tem, tradicionalmente, absorvido perferenciamente a mão de obra feminina. Ver ainda: MELO, Alex Fiúza de; FURTADO, Lourdes; MOURA, Edila e SÁ, Lucia (artigos etc.).

6 - Sobre a emergência de novos setores econômicos e relações de trabalho no Pará ver ainda os estudos: José Maria Quadros de Alencar - Os impactos so Projeto Albrás nas Relações de Trabalho no Estado do Pará. In: Amazônias em Tempo de Transição. Belém, UFPA, 1989; Edna Castro: IndustrializaTion et Rapports de Travail dans la Regin du Programme Grande Carajás. Paris, CBC/EHESS/CNRS,1994; Moacir/Evila e Edilza.

\section{Bibliografia}

ABREU, Alice. Mudança tecnológica e gênero no Brasil. Novos Estudos Cebrap., n.35, São Paulo, março/1993.

ACEVEDO, R. Tierras y afirmación politicade Grupos Rurales Negros en la Amazonia Brasilena, In:Después de la Piel, 500 anos de Confusión entre Desigualdad y Diferencia, Missiones, Revista Con-textos; 1994.

ACEVEDO, R. e CASTRO.E. Negros do Trombetas. GEU/UFPA. Belém. 1993.

AGIER, M. "Classe"ou "Raça"? Socialização, Trabalho eIdentidades Opcionais. Revista Análise \& Dados. O Negro.vol. 3, n.4, Salvador. 1994.

ARNAUD, E, CASTRO, E \& MAIA, Maria Lúcia. Utilização do Trabalho Feminino nas Indústrias de Belém e Manaus. Belém, Cadernos do SEPEQ/NAEA/UFPA, 1985.

BOURDIEU, P. O Poder Simbólico. Paris. Difel. 1989. 
CASTRO, Edna. Do Castanhal à Fabrica - padrões tecnológicos e formas de gestão. In: Novos Padrões Tecnológicos e formas de Gestão em Indústrias Brasileiras. USP/FEA/UNICAMP, São Paulo, 1989

Travail, Genre et Relations de Pouvoir dans le Carajas. In: Travail, Politique et Genre-Perspective Internationale. Cahiers du GEDISST n ${ }^{\circ}$ 910. Paris. GEDISST/IRESCO/CNRS, 1994.

Culture, Ethinicité et citoyenneté: dimensions des luttes sociales de Noirs Rémanents de "Quilombos". Bruxeles, CELA-IS/ UNIVERSITE LIbRE de BRUXELLES, 1995.

CASTRO, Nadya A. e BARRETO, Vanda S. de Sá. - Os Negros que dão certo: mercado de trabalho, mobilidade e desigualdades ocupacionais. Revista Brasileira de Estudos de População. V. 9, n. 2 Jul/dez 1992.

CHARLES, N. Gender divisions and social change, Harvester Wheatsheaf, Hemel Hempstead, 1993

GOSSELIN,D.I. e VAN HAECHT, A. (org.) - La réinvention de la démocratie. Ethnicité et nationalismes en Europe et dans les pays du Sud. L'Harmattan/Logiques Sociales. Paris, 1994

HUMPHREY, John. - Gender and Work in the Third World. Sexual Divisions in Brazilian Industry. London, Tavistock Publications. 1987

IBGE. Censos Demográficos - 1980/1991.

LOBO, E. A classe operária tem dois sexos. São Paulo. Brasiliense. 1991.

LOVELL, Peggy. A. Race, Gender and development in Brazil Latin Americain Reasearch Review. Vol 29, n 3, 1994

LOVENDUSKI, J. e PANDALL,V. Contemporary Feminist Politics. Oxfor. University Press. 1993.

MOORE,H.L. Feminism and anthropology. University of Minnesota Press, 1988

MOSER, Caroline. Gender planning and development. Theory, practice and training. London, Routledge, 1993

NASH, M. The cauldron of ethnicity in the moder world. Chicago. The University of Chicago Press, 1989

NEVES, Magda de Almeida. Trabalho e Cidadania.Os trabalhadores de Contagem. Vozes. Petrópolis. 1995. 
SANSONE, L. A produção de uma cultura negra - In:Estudos Afro-asiáticos. Cadernos Cândido Mendes. n²0, jun/1991.

STOLCKE, Verena. Sexo está para gênero assim como raça para etnicidade.In:Estudos Afro-asiáticos. Cadernos Cândido Mendes. n²0, jun/1991.

TELLES, E. Características sociais dos trabalhadores informais: o caso das áreas metropolitanas no Brasil. In. Estudos afro-asiáticos. n. 19. dez/1990.

SEADE/DIEESE/UNICAMP. Pesquisa de Emprego e Desemprego. Relatórios. n.40/41. 1992.

SEADE/DIEESE/UNICAMP. Pesquisa de Emprego e Desemprego. Principais resultados da Grande São Paulo. vol. n.113. 1994. 
